\title{
All in one Intelligent Safety System for Women Security
}

\author{
Abhijit Paradkar \\ ME Computer Engg student \\ K. J. Somaiya college of Engg., \\ Vidyavihar, Mumbai, India
}

\author{
Deepak Sharma \\ Associate Professor, \\ K. J. Somaiya college of Engg., \\ Vidyavihar, Mumbai, India
}

\begin{abstract}
According to the reports of WHO, NCRB-social-government organization 35\% Women all over the world are facing a lot of unethical physical harassment in public places such as railway-bus stands, foot paths etc. In this paper the authors have reviewed of various existing systems on women security. The authors have felt a need of advanced women security system to provides the safety measure in public places as well as travelling alone through public transports (school buses, company vehicle etc). This paper proposed a new model for the women security in public places which aims to provide the $100 \%$ safe environment.
\end{abstract}

\section{General Terms}

Women Security at public places.

\section{Keywords}

Security, Voice Recognition System, SOS key press, GSM (Global System for Mobile communication), GPS (Global Positioning System), Audio- Video Recording, Spy Camera Detection, Intrusion Detection Activity, Auto Call Receiving, Area Zone Module, Electric Shock for Self Defence, Screaming Alarm, Fake-Call Tool.

\section{INTRODUCTION}

India which sees itself as a promising super power and an economic hub can achieve its goal if and only if a large numbers of women participate in the development process. This paper presents an analysis review on the principal need of intelligence security system with technology requirement and challenges to build the system. Since the prediction of such incident is not possible hence to minimize the possibility of physical violence (robbery, sexual assault etc.) by keeping all the help tools ready to safely escape from violent situation. This reduces risk and brings assistance when needed. The social networking is the part of our life and also a source for women harassment by uploading the offensive photograph taken by hidden cameras, even though these cases might happen with innocence males, in some such cases these guys end their life by committing a suicide. The de facto spokesperson of United Nation Ban Ki-Moon, stated that "There is one universal truth applicable to all countries, cultures and communities: violence against women is never acceptable, never excusable, and never tolerable" [11]. The report of WHO states that. "A violence act against female gender disturbed the public health life of society and also it violates the human rights of women." [12].

This paper proceeds as follows. In Section 2 present the study of several existing systems with its functionality. Section 3 analyses the present systems critically based on cost factor. In Section 4 presents the proposed model. Section 5 discusses the working of proposed model. In Section 6 discusses the Working of Prototype developed. In section 7 the future scope of the proposed system is discussed. And finally in section 8 presents the conclusions of this paper.

\section{EXISTING SYSTEM}

The existing systems available and surveyed can be categorized into three ways as follows:-

\subsection{Type A) Systems designed as a mobile app for the android mobile}

The paper [1] proposes a voice keyword recognizing app to recognize the user and activate the app functionality even when the mobile keypad locked. The GPS module tracks the longitude and latitude to trace an exact location of a user and sends the pre-stored emergency message including location to the registered contact numbers. The Audio Recording module starts the recording of the conversation for five minutes and stored as evidences. The message goes in queue if network problem and send when network gets available. A notification is generated for successful deliver message. Also user can select contact through voice based contact list and make a call. Note: The spoken keyword converted into a text to compare with the registered keyword.

The paper [2] proposes an emergency response situation recognizing app called as IPROB to provide women safety even in the situation like terrorist attacks or natural disaster, by just shaking the mobile above the predefined threshold value automatically activate the system. It starts capturing the surrounding voice to test and confirm the unsafe IPROB situation where it raised the notification and user fail to respond in predefine time then the message alert sends to the register contacts. If the mobile profile at the receiver is in silent mode then convert it into the General profile to give the voice notification as "YOUR CHILD IS IN TROUBLE PLZ HELP...PLZ HELP ..." continuously like a ring tone, until they stop it. If a register contact confirms a PROB then appropriate emergency services like ambulance, fire brigade are alerted. If a register contact responds with an audible notification, then it automatically connects and enables the speakerphone at the victim side. An integrated tri-axial accelerometer used to evaluate the unique movements that a phone experiences as threshold.

The paper [3] proposes a SCIWARS app (Spy Camera Identification and Women Attack Rescue System) which consist of two modules. A first module act as an intelligent alerts system which detects the infrared rays coming from every Night-vision hidden cameras placed in changing roomshotels room etc and also informed the user about unsafe place through message. Now it's the user responsibility whether to register a complaint or not by forwarding the notification with the location to legal authorities such as Police. The second module will get activated by pressing any key continuously which will provide the help to the victim from physic attack in unsafe situation. It sends the emergency message containing location to register contacts. It also records the voice and captures the images of the surrounding for 45 seconds. This information also stored in secret location of mobile for future evidences. This app also able to converts the receiver mobile 
profile from silent to general mode, and also supports the auto-call receiving system at victim side.

The paper [4] proposes an android app to provide security at two different situations as follows. The First module provide security to Women at Emergency Situations propose a Save Our Souls (SOS) app to provides the security on a single click of SOS button for the women travelling at night or alone. No need to unlock the screen, instead by just pressing the power button it directly triggers the application to run at the background, to send the emergency message including the location in the form of latitude and longitude to the registered contacts. The second module proposes an android based home security system that provides security of house belongings and Senior Citizen in the user absence. Since the security of senior citizen is always a concern with increasing number of robbery incidents. This app informs the user about an attempt of intrusion activity at home through a message and a feedback SMS triggers an alarm in the house. The minimum requirement is the android mobile, a hardware circuit embedded with a switch and GSM modem that are connected to the door. When an intruder tries to open the door, the switch triggers an interrupt for the microcontroller to activate the GSM modem to send warning SMS to the store registered number in the modem. At the receivers end the application pop up the menu frequently for user attention. If the user fails to acknowledge in the defined time interval, then the automatic positive acknowledgement message get send to the remote GSM modem which in turn interrupt the microcontroller for an alarm.

The paper [5] proposes an app, in which a single click of SOS sends a message containing the location and/ or audio- video call to the guardian number. At receiver touch the location URL in the message to view it in the Google Map. It also provides different help tools like First-Aid help, Fake Call Help and video call. The First-Aid help tool provides the help on various health issue problems occurred at an accidental or emergency situation during the night time. First aid help for various problems are as: unconscious and not breathing, choking, bleeding heavily, burns, heart attack, diabetes etc. The Fake call help to escape from the meetings- parties at a time when women start feeling uncomfortable and think that, "if someone calls me then I can leave this place". Fake call rings tone same as that of normal incoming call ring and once call accepted it stop ringing. It also supports Fake Hang Up option. The guardian contacts are by-default for this app, but it able to search the cops, firemen, hospitals contacts nearby to your location. It also sends the audio-video recording via Email-Gmail of emergency situation taken by the user where user unable to speak or tell the circumstances.

\subsection{Type B) Systems designed as a device with the help of Microcontroller}

The IEEE real project [6] propose an automated highly reliable women security device which consist of the advanced sensors embedded in a wearable dresses. It consist of advanced sensors, GSM and ATMEGA8 microcontroller with ARDUINO tool which keep user under observation at all the time. It monitors the heart beat-rate, temperature and vibration in body through sensors to check for uneasy situation. In such situation it will activate the GPS module to track the location and wireless camera to capture the images that get send to the control room of the receiver through GSM modules to take necessary actions. At the same time processor activate the mice unit with amplifier which strengthens the voice of the women to screams or shout above the threshold limit.
The Paper [7] proposed a portable device as a belt which is automatically activated base on the pressure difference crosses over the threshold in unsafe situation. A GPS module track the location and sends the emergency messages to three emergency contacts every two minutes with updated location through GSM. The system also activates the screaming alarm that uses a siren, to call out for help and also generates an electric shock to harm the attacker for self-defense which may help the victim to escape. The device mainly consists of micro controller on the ATMega328 board which programmed using the ARDUINO programming language.

The paper [8] proposes the women security device called as "Suraksha" which is an easy to operate device. This device can be activated through- voice command, Press a switch key and shock (i.e. when the device is thrown with force, a force sensor used to activate the device). In emergency situation it will send the message including instant location to the police, via the transmitter module and registered numbers via a GSM module. Currently the work is under process to embed it in jewelries, mobile or other carrier like belt etc. It can play a major role in the propose projects where all the police stations are connected and share the criminal records, crime investigating cases etc.

The paper [9] proposes an extended vehicle tracking system to track the vehicle based on GPS with that it also provides the safety through an emergency button kept under the vehicle seat using GSM. As the increasing economic growth rate of a country, many companies are establishing their setup in the nearby region of the cities. Since, the security of women employees' inside the private transportation is the companies' responsibility.

In the unsafe situation an employee need to press the emergency button to activate the device Teltonika-FM1100. It in turn enables simultaneously the android device used to capture the images inside the vehicle and the GPS system which track the vehicle position in the form of latitude and longitude. An alert message including the location is send card to the company special team and nearby police station through GSM SIM. After that it is the responsibility of police squad and company team to handle the situation.

The security in the system can be further enhances by using Geo-Fencing software that uses the GPS and Google Earth to define the Area-Zone for a vehicle that act as a virtual barrier. An admin uses the tools provided by the software to set geographical boundaries which help to detect wherever a vehicle enters or leaves the customized geo-fenced area and restrict the drivers to travel from the sensitive zones. The admin can see the reports of vehicle position, speed, ignition status and travelling report and also instruct the driver on the speaker phone that is placed inside the vehicle.

[Note: The Teltonika-FM1100 device has a GSM SIM slot where one GSM SIM inserted to send and receive the messages. Another GSM SIM card is placed inside the android device of vehicle to exchange the images through messages or through email alert. The ignition system with GPS provides the status of the car as start or stop, it also track the location of vehicle after fix time interval to be viewed the position on Google map.]

\subsection{Type C) An advanced artificial intelligence security systems}

The paper [10] proposes the advanced automatic technique to predict the unsafe situation based on the female emotion as fear, anger etc. The system follows the steps given below to 
determine the chaotic situation under the surveillance region to identify the violence situation.

Step 1:- At a higher altitude camera2 placed to obtain the body movements as well as to provide the surveillance. If the population density calculated for a given frame contain more than fifteen individuals then such situations are not consider for further processing since the chances of attack in the crowded place are less. The Chaos analysed by comparing two successive equal sizes captured images through camera1 is place in such a way that it will captures the face emotion. For two persons, the camera field of view is divided into two regions to find out the distance between the individuals which get compare with pre-defined value called as threshold. If the variance is small indicating the safe distance whereas the large variance indicate the unsafe situation to activate the gender detection section.

Step 2:- It check the gender as male or female base on the facial features (correlation value) to identify at least one female to activate the system.

Step 3:- Facial Expression Reorganization System used to recognize the individual action base on the facial expressions by performing the following steps:-

1. Acquisition step: - It detects and captures the face (normally head position).

2. Extraction step: - To extract the features from image after pre-processing.

3. Gesture recognition step:- It provide intelligent ways to classifies feature into emotion reorganization feature to generate the fine face details as smile, fear and anger.

4. GSM module and alarm system: - If emotion on female face is detected as fear/ anger, and notification generated and send to the control room. Also it activates the surrounding siren. The system able to capture and store the face expression of suspect as for the evidences.

Since the system predicts about an unsafe situation hence require advance technology.

\section{CRITICAL ANALYSIS}

The above ten papers are analysed based on the parameter like shortcoming, vulnerabilities, cost and parameter that affect the cost.

Table 1: Critical Analysis Summary

\begin{tabular}{|c|c|c|c|}
\hline Ref & Shortcoming & Vulnerabilities & $\begin{array}{c}\text { Cost and } \\
\text { Parameter that } \\
\text { affect the cost }\end{array}$ \\
\hline$[1]$ & $\begin{array}{c}\text { Needs to } \\
\text { remember the } \\
\text { keyword for } \\
\text { activation. }\end{array}$ & $\begin{array}{c}\text { A system may } \\
\text { not recognize } \\
\text { the user, if noise } \\
\text { added with } \\
\text { voice. }\end{array}$ & $\begin{array}{c}\text { Cost-Free/ Very } \\
\text { Less. A } \\
\text { software } \\
\text { implementation } \\
\text { makes cost less. }\end{array}$ \\
\hline$[2]$ & $\begin{array}{c}\text { User should } \\
\text { remember the } \\
\text { Shaking way } \\
\text { to activate the } \\
\text { system }\end{array}$ & $\begin{array}{c}\text { A system may } \\
\text { not recognize } \\
\text { the threshold } \\
\text { when shaking } \\
\text { frequency gets }\end{array}$ & $\begin{array}{c}\text { Cost-Medium. } \\
\text { An integrated } \\
\text { tri-axial } \\
\text { accelerometer } \\
\text { evaluates the }\end{array}$ \\
\hline
\end{tabular}

\begin{tabular}{|c|c|c|c|}
\hline & & varies. & threshold. \\
\hline [3] & $\begin{array}{c}\text { Receiver } \\
\text { profile } \\
\text { checked and } \\
\text { converted to } \\
\text { General. }\end{array}$ & $\begin{array}{l}\text { The infrared } \\
\text { coming from } \\
\text { other device can } \\
\text { be generating } \\
\text { the noise signal. }\end{array}$ & $\begin{array}{l}\text { Cost-Medium. } \\
\text { An infrared } \\
\text { signal detecting } \\
\text { system detects a } \\
\text { hidden camera. }\end{array}$ \\
\hline [4] & $\begin{array}{c}\text { Switches } \\
\text { replaced with } \\
\text { advance } \\
\text { sensors. }\end{array}$ & $\begin{array}{l}\text { If door try to } \\
\text { open by pet / } \\
\text { dog may be } \\
\text { result as } \\
\text { intrusion } \\
\text { activity. }\end{array}$ & $\begin{array}{l}\text { Cost- High. } \\
\text { Android mobile } \\
\text { with that } \\
\text { embedded } \mathrm{h} / \mathrm{w} \\
\text { of Switch and } \\
\text { GSM modem. }\end{array}$ \\
\hline [5] & $\begin{array}{l}\text { For SOS key } \\
\text { press mobile } \\
\text { must be in } \\
\text { reach at } \\
\text { emergency. }\end{array}$ & $\begin{array}{l}\text { In First-Aid help } \\
\text { Tool not provide } \\
\text { the nearby } \\
\text { hospital } \\
\text { information }\end{array}$ & $\begin{array}{c}\text { Cost- Free/ } \\
\text { Very Less. Due } \\
\text { to software } \\
\text { development. }\end{array}$ \\
\hline [6] & $\begin{array}{c}\text { Sensors } \\
\text { makes as a } \\
\text { dedicated } \\
\text { wearable } \\
\text { device. }\end{array}$ & $\begin{array}{l}\text { The other device } \\
\text { vibration or } \\
\text { invisible ray } \\
\text { may affect the } \\
\text { system. }\end{array}$ & $\begin{array}{l}\text { Cost- Very } \\
\text { High. Intelligent } \\
\text { sensors for } \\
\text { heartbeat, } \\
\text { vibration body. }\end{array}$ \\
\hline $\begin{array}{l}\text { [7] } \\
\end{array}$ & $\begin{array}{l}\text { An alarm } \\
\text { Module } \\
\text { needed for } \\
\text { help. }\end{array}$ & $\begin{array}{l}\text { In crowded train } \\
\text { or bus the } \\
\text { system get } \\
\text { activated. }\end{array}$ & $\begin{array}{l}\text { Cost-High. } \\
\text { Hardware with } \\
\text { assembly } \\
\text { program. }\end{array}$ \\
\hline $\begin{array}{l}{[8]} \\
\end{array}$ & $\begin{array}{c}\text { A very small } \\
\text { size makes it } \\
\text { as a dedicated } \\
\text { device. }\end{array}$ & $\begin{array}{l}\text { If any modules } \\
\text { fail need to } \\
\text { replace entire } \\
\text { system. }\end{array}$ & $\begin{array}{l}\text { Cost- High. } \\
\text { Nano technology } \\
\text { helps to embed it } \\
\text { in jewelry. }\end{array}$ \\
\hline [9] & $\begin{array}{l}\text { Require one } \\
\text { switch per } \\
\text { seat person. }\end{array}$ & $\begin{array}{l}\text { A provision for } \\
\text { by mistaken } \\
\text { activation. }\end{array}$ & $\begin{array}{l}\text { Cost- Very } \\
\text { High. Security } \\
\text { staff salary. }\end{array}$ \\
\hline [10] & $\begin{array}{c}\text { An area } \\
\text { covered by } \\
\text { intelligent } \\
\text { Surveillance } \\
\text { system is } \\
\text { limited. }\end{array}$ & $\begin{array}{l}\text { The enjoyment } \\
\text { "Masti" with } \\
\text { friends at public } \\
\text { places may } \\
\text { recognize as } \\
\text { Chaos. }\end{array}$ & $\begin{array}{l}\text { Cost- Very Very } \\
\text { High. Advanced } \\
\text { image } \\
\text { Processing and } \\
\text { Gender detection } \\
\text { software. }\end{array}$ \\
\hline
\end{tabular}

[Note: - Cost mentioned above is categories based on the present currency rate as 1 Doller $(\$)=$ Rs 64

Very Less=under Rs 200; Medium=Rs 200 to Rs1000; High=Rs 1000 to Rs 5000; Very High= Rs 5000 to Rs 20000; Very Very High=Rs 20000 to Rs 100000] 


\section{PROPOSED MODEL}

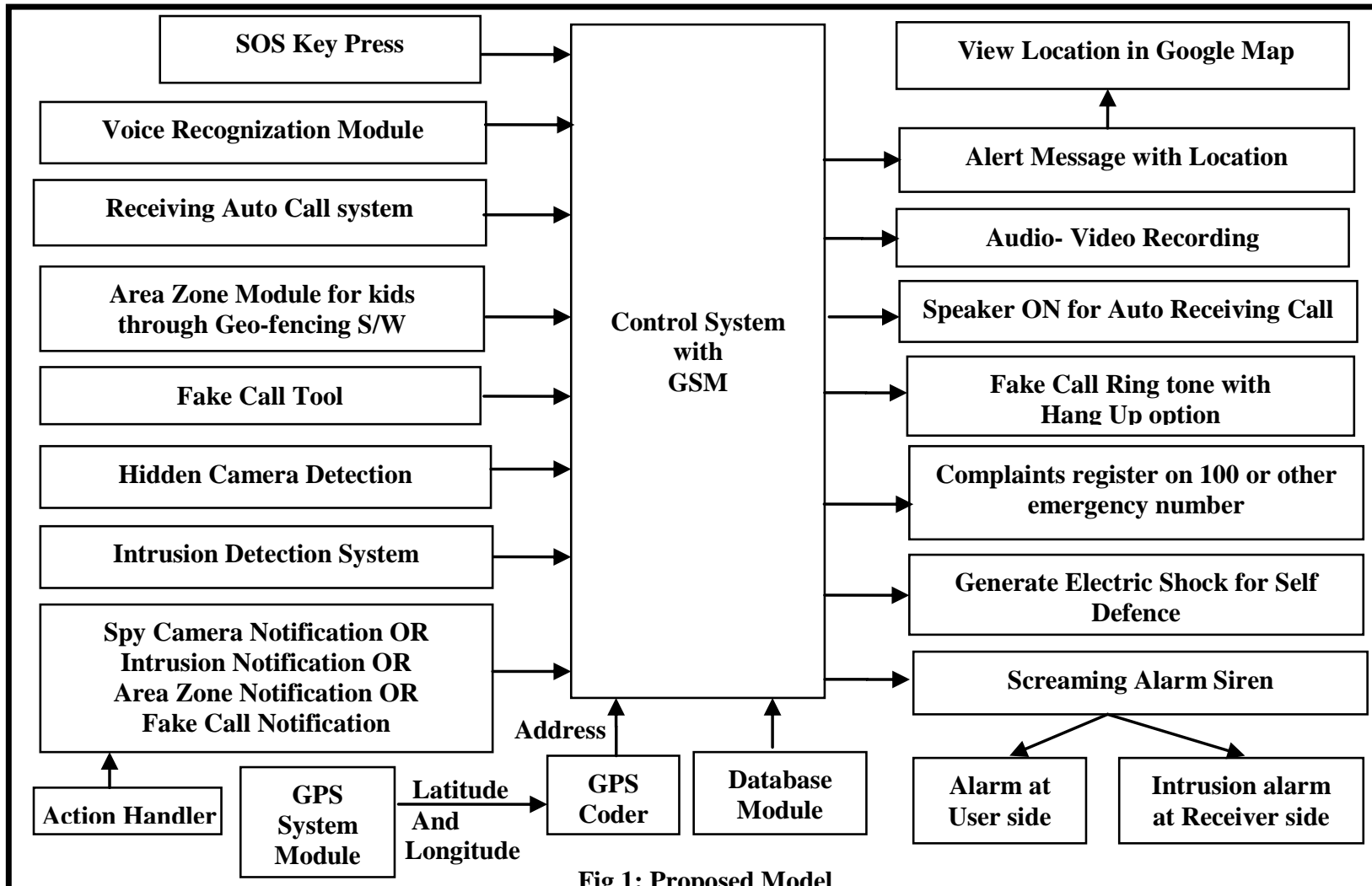

Fig 1: Proposed Model

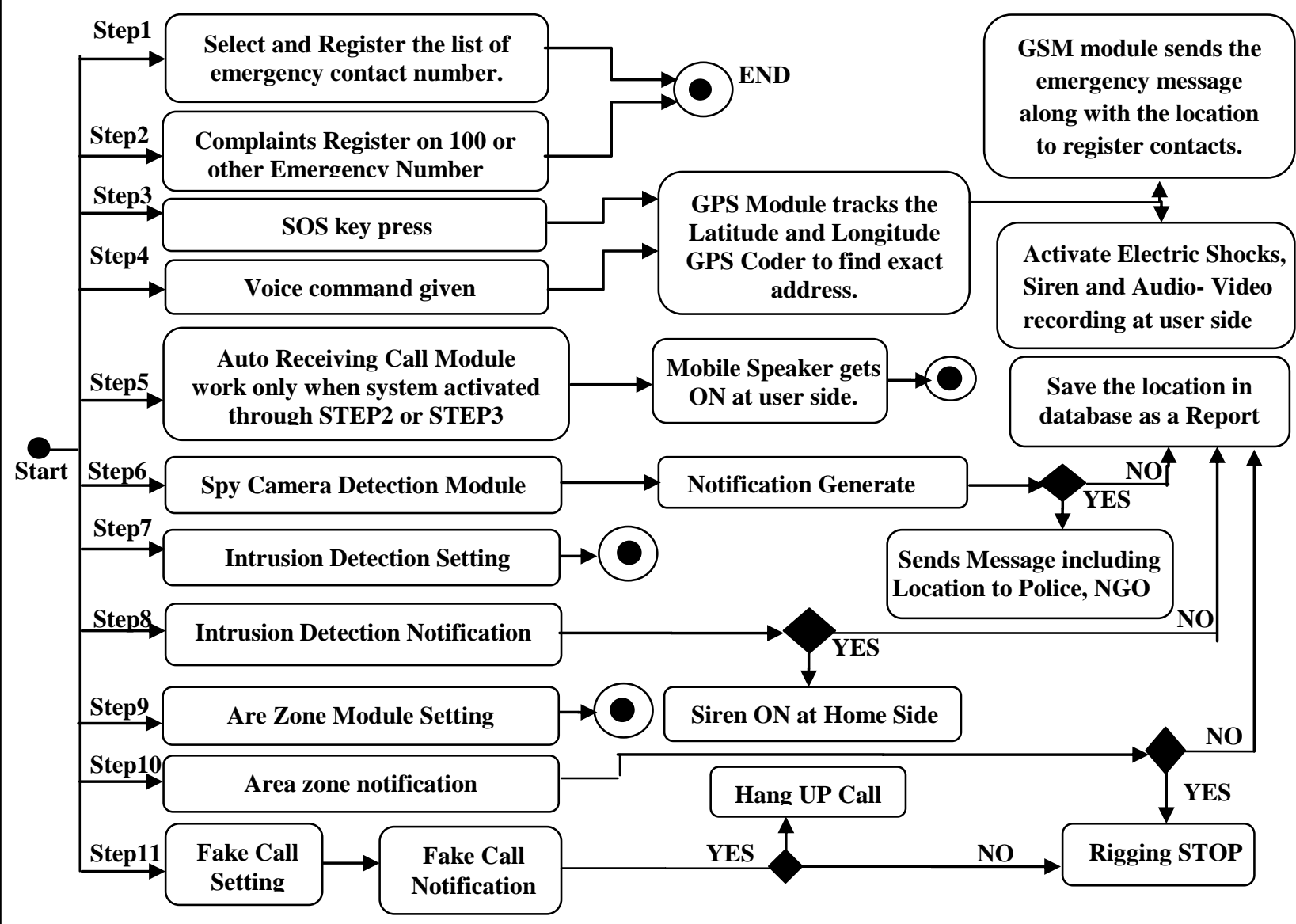

Fig 2: Activity Diagram 


\section{WORKING OF PROPOSE MODEL}

Base on the critical analysis and the requirement of safety functionality the modules are selected as shown in figure 1 and the work flow called as activity diagram as shown in figure 2 . The working of selected modules is as follows:

Database Module:-The user needs to register the emergency contact numbers with the system which are stored in Register Contact Database. A voice keyword needs to be register with the system. It also store the notification generated by various modules as a report of evidences. It used SQLite database.

SOS Key Press Module and Voice Recognization Module:-

Any one action can be activates the system, which sends the message including the user location to the registered contacts. At the receiver, just by clicking on the location ink provided in the message it can show the location on the Google map.

Auto receiving call module: - After receiving the notification if register contact make the return back call then the call is get accepted without manual interaction at the user side and makes the speaker phone ON.

Global Positioning System (GPS) module: - It is a navigation and precise positioning tool, tracks the location in the form of longitude and latitude based. The GPS Coder Module used this information to search an exact address of that location as the street name, nearby junction etc. In case where GPS is disabled then the system will only send the longitude and latitude. Internet is mandatory.

GSM System Module: - Global System for Mobile communication (GSM) SIM card is inserted inside the mobile device to send and receive the messages using GPRS. The GSM SIM card number is registered with the system. With increasing usage of GSM, network services are expanded beyond speech communication to incorporate many other custom applications, machine automation and machine to machine communication.

Spy camera detection module: - It detects the infrared rays coming from every Night-vision hidden cameras placed in changing rooms- hotels room etc. in such cases it traces the location using GPS module and send the notification to the user about unsafe place. It depends on the user to register the complaint base on notification.

Intrusion Detection Module:-The minimum requirement is the android mobile device, a hardware circuit with a switch and a GSM modem embedded should be installed and connected to the door of the house. When the intruder tries to open the door, the switch triggers an interrupt for the microcontroller to trigger the GSM modem to transmit a warning SMS to the registered number store in the modem. At the receivers end the application pop up the menu frequently. It wait the user (for pre determine time) to acknowledge, if user fail to respond then the system consider the positive feedback and sends to the remote GSM modem to interrupt microcontroller to activate the alarm at home side. This siren makes the attention of other people towards the intrusion activity.

Area zone module: - User has to set the range through setting and attached the nano sensor on to the kid cloths or jewellery. Whenever kid goes out of that range, then system triggers the alarm at user side. It works same as that of RFID (radio frequency identification).
Fake call Tool Module: - It helps to escape from the meetings, parties at a time when women start feeling uncomfortable and started feeling that how can I left this place? Someone call me will help me out. In such cases user can set the time interval in the tool to get Fake Call. It gives the ringing tone in same way as the normal call does. It also supports the Hang up option.

Action after getting the Handler Notification: - The notification is accepted (by pressing YES) or rejected (by pressing NO). In case of acceptance of intrusion notification the siren at the house gets activated. In case of acceptance of spy camera notification a complaint is register by forwarding the notification to legal authority such as Police. In case of acceptance of notification of Area Zone Notification OR Fake Call Notification the siren or Fake Call ringing get stopped.

Audio and video recording module: - As soon as the system activated Audio Recording module will start the recording of the conversation take place at that situation for five minutes and stored in mobile database as well as mail it to register email account. This recording will be used as evidence.

Call on 100 or other emergency number: - A call on100 itself register the complaint hence all cases of harassment should be register on 100 as an evidence of complaint registration which enforce the police to perform necessary action.

Generate Electric Shock for Self Defence module: - It helps the user to self defence and run away from the place. Also help to call for help.

Screaming Alarm Siren module: - It makes the alarm at "user end" whenever user activates the system through the SOS button or through voice command. In case of the intrusion activity the alarm siren generated at the home side.

\section{WORKING OF PROTOTYPE DEVELOPED}

The proposed system can be implemented as an android app application or using Arduino based board. The proposed system provides all required functionality and there is no need to buy and install different apps that possess different functionality. Hence the cost gets minimized as well as the memory requirement by the system is less compared to having many apps. The working of the system is as follows:

The Main Form of the system graphical user interface (UI).

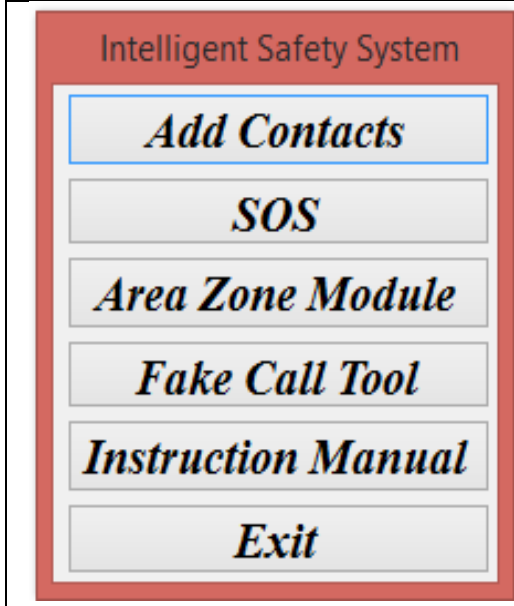


Select the option as "Add Register Contact" from Main Form. Now user will get two options on FORM-1 as to "add from existing phone list" or "as new contact".

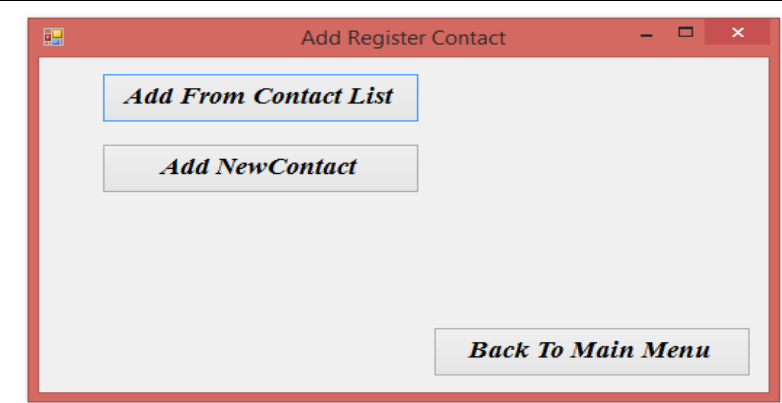

Select the option as "Add From Contact List" from FORM-1.

Select the contacts to register with the system and click on the

"Add Selected Contacts" the notification message generated as the follow.

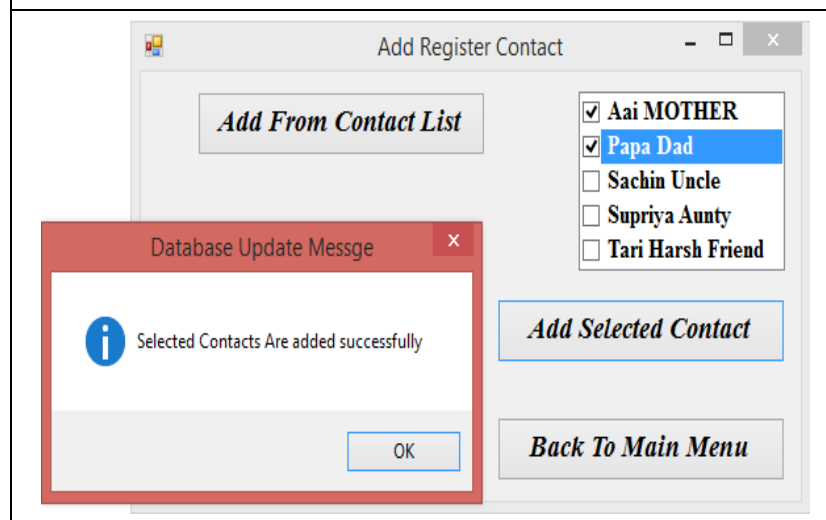

Select the option as "Add New Contact" from FORM-1, if anyone want to register the person whose details is not there in phone book.

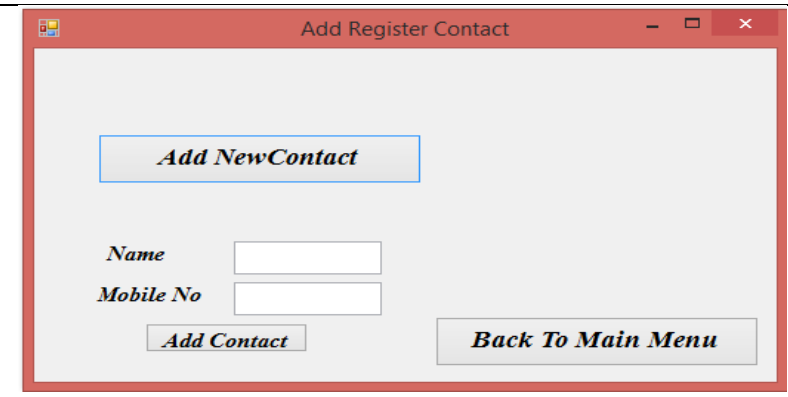

Select the option as "SOS" from Main Form. It will send the emergency message including the location to the register contact numbers and notification at user side as shown below.

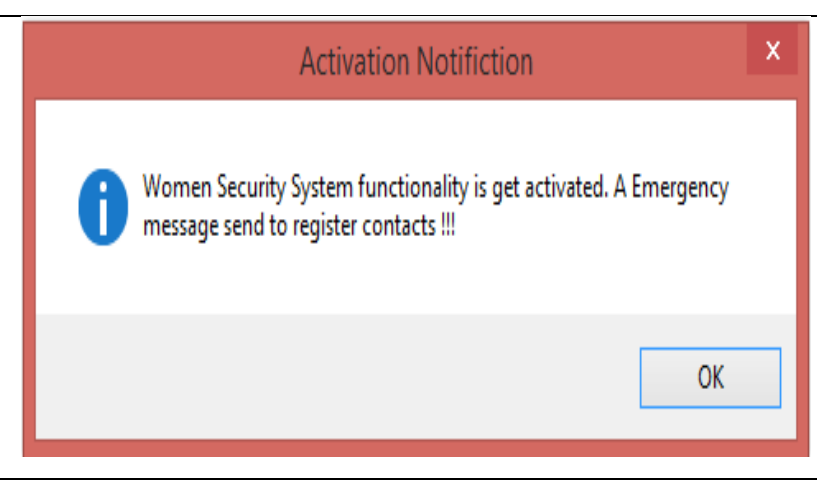

Select the option as "Area Zone Module" from Main Form. It will display the setting as range of circle in meters. If a small kid goes out of range it will generate the alarm.

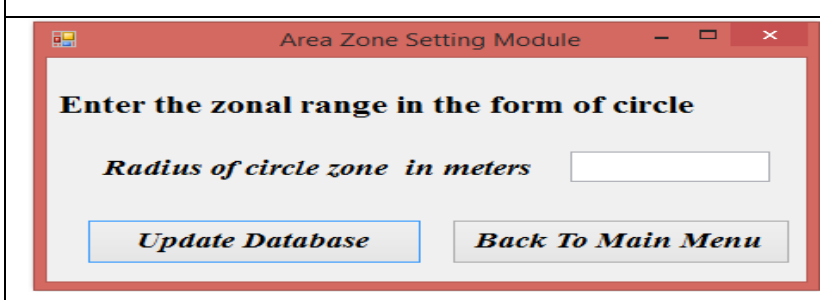

Select the option as "Fake Call Tool" from Main Form. It will generate the Fake- Call as per the timer set by the user. Example. Here the timer set after 2000 milliseconds.

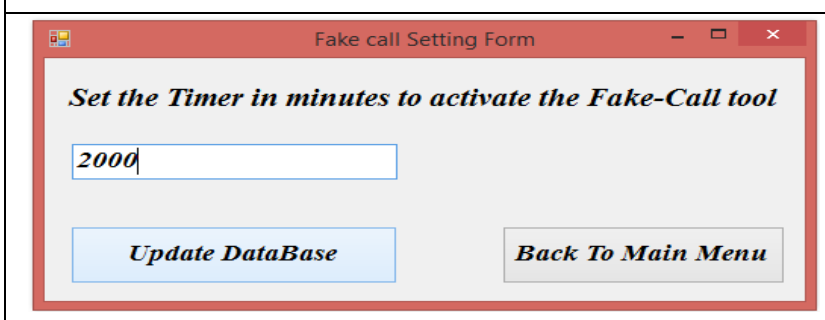

Now Click on "Update Database" to activate the Timer, the notification shown below.

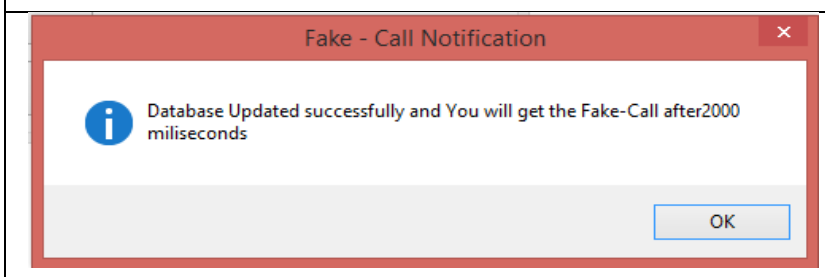

The Fake Call with Hang-UP option message Notification generated are as shown below.

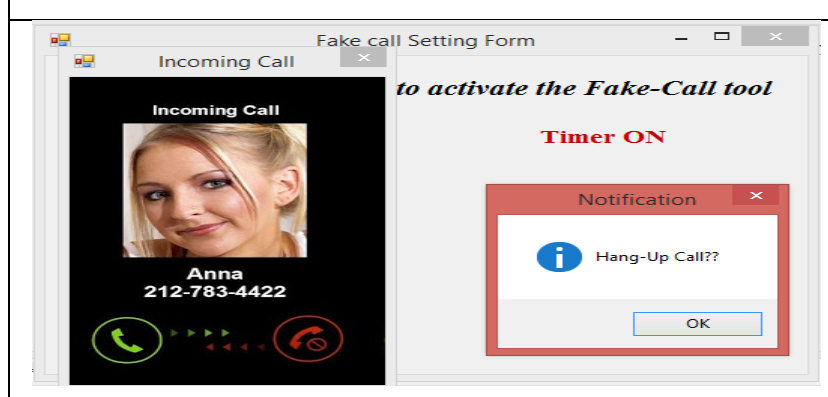

Select the option as "Instruction Manual" from Main Form.

It will display the instruction manual set to guide the user.

Instruction Manual
Instruction Manual Guide for user
1. Save valid mobile numbers as a Register contacts.
2. Press SOS button to activate the System.
3. Area Zone Modle to Decide the area Zone of small Kids.
4. Fake Call help you to escape from parties when you want.
5. Press "Exit" to close the application.
Back To Main Menu




\section{FUTURE SCOPE}

As the technological changes or new requirement from user to enhance the functionality of product may requires new version to introduce. Although the System is complete and working efficiently, new modules which enhance the system functionality can be added without any major changes to the entire system. By keeping this ability of the product I mind, an incremental process model has been used to design and develop the system. Among the various modules few are identified, which couldn't be included in the last increment due to time constraints. These are as follows

\section{Primary School Children Safety:}

As the school children safety are major concerns for parents as well as school management due to the recent incidents of child crimes like children missing, abuse etc. This module monitors the child safety when they are travelling in school buses. Once they reached the school the device gets deactivated by school authority and message send the parents that, "the child reaches the school safely". At return journey again the device is activated by school authority and when they reached the home, the acknowledge message is send to the school when parents deactivate the device. The device is capable of audio recording when activated that can be listening by the parents or authorize person.

\section{Vehicle Safety System Module:}

The Safety of four wheeler car is also a major concern in the society due to the increase in the crime rate of stolen car. The intrusion detection module can be modified according to the requirement of vehicle safety system module.

Mobile and other valuables Safety System Module:

The missing rate of mobiles is high while travelling from bus, train or crowed public area. The area zone module functionality further enhances to provide safety. A small device needed to keep either in same pocket or within the range of few centimeters. As you kept the mobile and forget to pick up or someone stolen it then de to small range the siren of mobile as well as device gets $\mathrm{ON}$ for user attention.

Also the same device can attach to our luggage, hence in case of forgetting to pick back or try to stolen by someone can be easily noticed by the module and make the attention of user through the siren alarm.

Hence, the advance technology makes the system more robust and reliable. As the new modules provide the functionality which enhance the safety and security. Thus it helps to fulfill the purpose of the project.

\section{CONCLUSION}

It can be concluded that the system helps to supports the gender equality by providing safe environment to women in the society, and allows them to work till late nights. Anyone before doing any crime against the women will be deterred and it help reducing the crime rate against the women.

In some of the cases the system can provide useful evidences. Since the system can do audio-video recording of incidences which can act as the evidences.

The proposed system provides the tool for intrusion detection inside the home where senior citizen, handicapped person or women leaving alone and after detection of intrusion it takes necessary preventive measure action to ensure safety.
The proposed system provides the tool to detect the spy camera placed at hotel, changing room and in form the user about the same, and hence provide safety from capturing the offensive photograph or videos. Someone can use such videos or photograph to exploit some ones identity or to blackmail to make a profit from it.

The propose system provides the area zone modules to provides the child security and surveillance such as the child abuse and child missing crime rate in the society is high and protection measure is needed to provide them a safety.

The limitation of the devices can be overcome by storing the data onto the cloud. There is a need to make such systems standard and get approval from government, so that courts accept the evidences.

Women's security is a critical and social issue in today's world. The crime (molestations, robbery, sexual assault, rape, domestic violence) against the women can be now brought to an end with the help of real system implementation of propose model.

\section{ACKNOWLEDGMENTS}

I extremely grateful and convey my heartfelt thanks to internal guide Professor Deepak Sharma work under the Department of Computer Engineering, K. J. Somaiya College of Engineering Vidyavihar Mumbai for his valuable suggestions and encouragement throughout all the development stages of this paper.

My special votes of thanks to former president APJ Abdul Kalam sir to give us a "VISION 2020"- to make developed and powerful nation India, up to the year 2020. This dream of visions encourages me to work on different social issues in the society and search the solution on those issues. A women safety problem can be solved using proposed system.

My vote of thanks to Prof. Manish Pote work under the Department of Computer Engineering, K. J. Somaiya College of Engineering Mumbai, for their guidance on "How to Read a research Paper in three passes which will help to extract the required content", based on S. Keshav [14] published paper.

My vote of thanks to Prof. Prasanna Shete work under the Department of Computer Engineering, K. J. Somaiya College of Engineering Mumbai for his valuable suggestions.

At the last phase of this paper, my vote of thanks to the editor of IJCA and other team members of IJCA publication for their valuable suggestion, encouragement and the support to make the necessary changes before publishing of this paper.

\section{REFERENCES}

[1] Dongare Uma, Vyavahare Vishakha and Raut Ravina, "An Android Application for Women Safety Based on Voice Recognition", Department of Computer Sciences BSIOTR wagholi, Savitribai Phule Pune University India, ISSN 2320-088X International Journal of Computer Science and Mobile Computing (IJCSMC) online at www.ijcsmc.com,Vol.4 Issue.3, pg. 216-220, March- 2015

[2] MAGESH KUMAR.S and RAJ KUMAR.M, "IPROB EMERGENCY APPLICATION FOR WOMEN", Department of Computer science Sree Krishna College of Engineering Unai village Vellore (TN) India, ISSN 2250-3153 International Journal of Scientific and Research Publications, online at the link www.ijsrp.org , Volume 4, Issue 3, March 2014. 
[3] Vaijayanti Pawar, Prof. N.R.Wankhade, Dipika Nikam, Kanchan Jadhav and Neha Pathak, "SCIWARS Android Application for Women Safety", Department of Computer Engineering, Late G.N.S.COE Nasik India, ISSN: 2248-9622 International Journal of Engineering Research and Applications Online at the link www.ijera.com, Volume 4, Issue 3(Version 1), pp.823826, March 2014.

[4] Bhaskar Kamal Baishya, "Mobile Phone Embedded With Medical and Security Applications", Department of Computer Science North Eastern Regional Institute of Science and Technology Nirjuli Arunachal Pradesh India, e-ISSN: 2278-0661 p- ISSN: 2278-8727 IOSR Journal of Computer Engg (IOSR-JCE) www.iosrjournals.org, Volume 16, Issue 3 (Version IX ), PP 30-3, May-Jun. 2014.

[5] Dr. Sridhar Mandapati, Sravya Pamidi and Sriharitha Ambati, "A Mobile Based Women Safety Application (I Safe Apps)", Department of Computer Applications R.V.R \& J.C College of Engineering Guntur India, eISSN: 2278-0661, p-ISSN: 2278-8727, IOSR Journal of Computer Engg (IOSR-JCE) www.iosrjournals.org, Volume 17, Issue 1 (Version I), PP 29-34, Jan.-Feb. 2015

[6] THOOYAVAN V, “ADVANCED SECURITY SYSTEM FOR WOMEN", Department of ECE Vidyaa Vikas College of Engineering and Technology Vasai Thane India, Final year project, Serial number HEM 128 IEEE 2014 Project List under real time target surveillance system, slides share on www.slideshare.net, Jun 24, 2014.

[7] Prof. Basavaraj Chougula, Archana Naik, Monika Monu, Priya Patil and Priyanka Das "SMART GIRLS SECURITY SYSTEM", Department of Electronics and telecommunication KLE's College of Engineering and Technology Belgaum India, ISSN 2319 - 4847 International Journal of Application or Innovation in Engineering \& Management (IJAIEM) Web Site: www.ijaiem.org, Volume 3, Issue 4, April 2014.
[8] Nishant Bhardwaj and Nitish Aggarwal, "Design and Development of "Suraksha"-A Women Safety Device", Department of Electronics and Communication ITM UNIVERSITY Huda Sector 23-A Gurgaon Delhi India, ISSN 0974-2239 International Journal of Information \& Computation Technology online available at http://www. irphouse.com, Volume 4, pp. 787-792, November 2014.

[9] Poonam Bhilare, Akshay Mohite, Dhanashri Kamble, Swapnil Makode and Rasika Kahane, "Women Employee Security System using GPS And GSM Based Vehicle Tracking", Department of Computer Engineering Vishwakarma IOT Savitribai Phule Pune University India, E-ISSN:-2349-7610 INTERNATIONAL JOURNAL FOR RESEARCH IN EMERGING SCIENCE AND TECHNOLOGY, Volume-2, ISSUE-1, JAN-2015.

[10] Remya George, Anjaly Cherian.V, Annet Antony, Harsha Sebestian, Mishal Antony and Rosemary Babu.T, "An Intelligent Security System for Violence against Women in Public Places", ISSN: 2249 - 8958 International Journal of Engineering and Advanced Technology (IJEAT), Volume-3, Issue-4, April 2014.

[11] Report of the Fourth World Conference on Women. New York, United Nations, 1995 (A/CONF.177/20/Rev.1) (http://www.un.org/womenwatch/confer/beijing/reports/, accessed 1 April 2013).

[12] World Health Organization, "Global and regional estimates of violence against women: prevalence and health effects of intimate partner violence and nonpartner sexual violence, Geneva: WHO (2013).

[13] A.P.J. Abdul Kalam and Y.S. Rajan, "INDIA 2020A Vision for the New Millennium", Penguin Books India Pvt Limited 11 Community Centre Panchsheel Park New Delhi 110017 India, Published by Penguin Books 2002.

[14] S. Keshav, "How to Read a Paper", David R. Cheriton School of Computer Science, University of Waterloo Canada,keshav@uwaterloo.ca. 